\title{
COASTAL SOCIO-ECOLOGICAL SYSTEM ASSESSMENT IN MUNICIPALITIES: SYSTEM DYNAMICS MODELLING APPLICATION IN LATVIA
}

\author{
IVETA ŠTEINBERGA, IVARS KUDREN̦ICKIS \& RAIMONDS ERNŠTEINS \\ Environmental Science Department, University of Latvia, Latvia
}

\begin{abstract}
Understanding functionality of coastal ecosystem and, specifically, coastal socio-ecological system (SES) and its governance from environmental, social and economic point of view at existing state is challenging and complex. Also, analysing future scenarios under various stressors could be solved only at site level or by using complex mathematical systems for the wider area. SES based tool is Systems Analysis Framework (SAF) methodology that includes definition of system borders, relevant system elements, flows and interactions within the system, and understanding of all these aspects. The methodology also includes identification of crucial components, as well as building of model, testing and verifying processes. Coastal ecosystems are very sensitive to various factors, such as environmental changes and, particularly, anthropogenic impacts. Even minor changes in temperature, salinity and nutrient availability can lead to substantial changes in life cycle. For example, the runoff can result in higher nutrient and/or pollutant levels in coastal waters - algae blooms can be dangerous to both humans and marine life. While coastal ecosystems should be prevented by special care, they are still very popular as a tourist destination. That causes requirement to link tourism impact to any other environmental impact and, vice versa, to estimate coastal state as promoter of tourism. This paper describes systemic approach used for the Baltic Sea coast at the local Salacgrivva municipality level in Latvia in the case of topical municipal development scenario of coastal tourism perspective. All impacts are modelled and evaluated with STELLA software.
\end{abstract}

Keywords: coastal management, Systems Approach Framework, system dynamics modelling, Latvia.

\section{INTRODUCTION}

Numerous studies of coastal ecosystems [1]-[4] shown substantial role of these ecosystems as socioeconomic systems, interacting with environmental stressors. These socioeconomic systems should be evaluated from spatial and temporal point of view. Integrated environmental management of coastal ecosystems could be performed by understanding the links between ecosystem services and their social effects. To ensure successful policy implementation it should include a participatory approach, integrating social and ecosystem considerations into climate adaptation measures. Moreover, it is essential to involve stakeholders in environmental management and decision-making. Adaptation to the climate change includes evaluation of the risks for coastal ecosystems through direct impacts that could result in various ways: (1) loss or changes to habitats and their associated organisms; (2) warming could force species to move to higher latitudes or elevations to maintain the same environmental temperatures; (3) sea level rise will be accompanied by saltwater intrusion into freshwater habitats, and, as a result, some could be forced to relocate or die, thus removing predators or prey that are critical in the existing food chain [5].

At the same time, the problem of integrative assessment of much more complex socioecological systems (SES) (more specifically, socioeconomic-ecological systems) that change under natural and anthropogenic drivers, is much less studied and modelled. This article covers complex assessment of coastal socio-ecosystem in local municipality of Salacgrīva (Latvia), done by Systems Approach Framework (SAF) methodology. This methodology was used in order to understand the system model that was built by STELLA software. SAF 
common approach and our applied governance basic principle (that coastal area is governed as socio-ecological system (SES)) were used to develop system dynamic coastal territory characterizing model and to assess the most essential SES functioning and its development components. In general, 40 parameters were selected and included in the model, characterizing (both in general and also specifically) all three sustainable development basic dimensions of concrete coastal territory as mandatory: environmental quality, economic and social sphere, and governance dimension.

This research was conducted with some specific purposes: (1) to identify and describe key drivers for selected territory - Salacgrīva, Latvia; (2) to build system dynamic model and test it under real world conditions; (3) to select one locally interested and possible development scenario for local coastal municipality (in this case, tourism increase) and to quantify it; (4) to model expected changes in coastal socio-ecological system and formulate consequences. Built conceptual complex model system, currently including 15 different variables, shows progress in applied research fields connecting basic local municipal development dimensions - environmental/natural, social, economic and governance fields. Moreover, in order to be designed, the model shall be flexible and open. Eventually, after some revisions, the model should be available for other territories and different scenarios, depending on new specifics.

\section{MATERIALS AND METHODS}

\subsection{Study site description: Salacgrīva coastal municipality}

Salacgrīva coastal municipality is located in the northeastern part of Latvia, in Vidzeme region $\left(57^{\circ} 45^{\prime} 6^{\prime \prime} \mathrm{N}, 24^{\circ} 21^{\prime} 26^{\prime \prime} \mathrm{E}\right)$. It has a border with Estonia and stretches along the Baltic Sea coast for $55 \mathrm{~km}$ (covering around 10\% of Latvia's coastline), but extends inland only for $5-15 \mathrm{~km}$. Salacgriva town is the centre of the area, located in the mouth of Salaca River. The total area of Salacgrīva municipality is $637.6 \mathrm{~km}^{2}$, but, according to statistical census in 2015 , population for this long coastal territory is only 8,685 inhabitants, with average population density of 14.8 inhabitants $/ \mathrm{km}^{2}$. Dominating commercial activities are connected with Salacgrīva port and export of timber, woodworking industry and food production. The port is located in $100 \mathrm{~km}$ from the capital Riga and $13 \mathrm{~km}$ from the border with Estonia. Its inland territory in Salacgrīva is 14.4 ha, in the sea -28.6 ha. There are six fully functioning berths in the port, and the main activities are cargo handling, fishing and vessel mooring.

\subsection{The Systems Approach Framework (SAF) methodology}

Systems analysis, as well as participatory systems approaches, applying system dynamics for urban and countryside planning, are widely known and generally used [6], [7]. In the described study, specialized methodological approach was used for system research - System Approach Framework (SAF). It has been developed and approbated in several European Union cooperation research institutes and universities, with the focus on coastal problems analysis. Particularly, SAF [8] was developed within the EU SPICOSA project as a practical tool for integrated coastal zone management, including possible and probable future scenarios, managing and forecasting eventual activity. SAF is based on coastal socioecological system (SES) approach. In order to improve the zone's ecological sustainability, economic efficiency, and social equity, it provides multidisciplinary advice to environmental managers and policymakers, concerning with environmental problems in the coastal zone.

Second SAF key requirement is that during the SAF application a considerable cooperation and consultation between the relevant stakeholders (end-users, policy makers, 
scientists, governance agencies, other relevant institutions, and nongovernmental organizations) should be included. To sum up, the general task of SAF is to ensure methodology providing framework conditions for cooperation of coastal society target groups. It would be based on the multi-thematical analysis and discussion of complex natural scientific and social scientific studies results. The aim of the methodology is to jointly develop proposals and to agree on how to improve ecological sustainability, economic efficiency and social equality of the particular territory [9]. The methodology contains four main steps: system design, formulation, appraisal, and output.

\subsection{Design of system dynamics model}

In the first step of SAF we identified and characterised local bottom-up governance elements. Also, top-down governance institutions are characterised. Thus we offer the overall institutional and stakeholders environment, in which SAF method is implemented. The generic lessons can be drawn out from our approach on problem analysis, adopted from general SAF method. As there is no single dominating problem, the negative environmental and socioeconomic impacts are caused due to synergy effects of a number of problems. The 1st part of SAF consists of: (1) issue identification; (2) identifying all stakeholders (stakeholder mapping); (3) holding the first stakeholder meeting; (4) institutional mapping; (5) describing the cause-effect chain; (6) listing the main ecosystem goods, services and economic drivers.

In order to study complex problems and environmental systems, it is possible to use both models of specific fields (air quality, water dynamics, etc.), descriptive statistical analysis methods, and system dynamics methodology models. Systems dynamics is a stock-flow methodology that helps to explore complexity, interconnectedness, and change over time. Because of their structural simplicity, usage convenience and open system, system dynamics models are becoming more and more popular in the spatial development research. They simulate different development scenarios and potential impacts in environmental, economic, and social fields. In the system dynamics modelling, it is assumed that behaviour of the system depends not only on its components' (attractors') behaviour, but also on their mutual interactions [10]. By using essential basic indicators or criteria describing system behaviour, based on scenarios included in system dynamics models and gained modelling results, it is possible to study more deeply and develop hypothetical governance system change before implementation process.

In general, 40 parameters were selected and included in the model, characterizing all three sustainable development basic dimensions of concrete coastal territory - both in general and, specifically, in environmental quality, economic and social sphere. Thus the second step of SAF includes: (1) system definition; (2) conceptual model; (3) data and methods; (4) problem scaling.

Traditionally, this type of modelling is a five-step process that is performed as follows: (1) defining the problem and the goals; (2) understanding the real life system, figuring out crucial components of the system; (3) building the model with connections between model variables; (4) testing and revising the model, and (5) verifying the model. STELLA model for Salacgrīva case study was selected also according to literature analysis. Various publications show successful usage of STELLA model in coastal development research and SAF methodology application [11]-[15]. 


\subsection{Scenario description}

As coastal tourism in the municipality is extended for $55 \mathrm{~km}$ along eastern coast of Riga Bay of the Baltic Sea, it may improve economic development. Therefore, this scenario has been selected for further territory development and investigation. For Salacgriva case analysis it is assumed that number of visitors could increase by $30 \%$ in the future (until 2020). Model with existing data has been developed for baseline scenario. Data selection and covered periodare data-dependent, e.g. climatological data are analysed for at least 30 years' period to see trends, while changes in air pollution sources are analysed only for last 15 years. Data selection is defined by scenario. In Salacgrīva case, the coastal tourism development by $30 \%$ increase was selected as more reliable scenario. Respectively, tourism increase is linked to wide versa parameters, e.g. change of visitors, number of mobile toilets, number of equipped places (for passenger cars), traffic flow impact as increase of noise and air pollution sources, etc.

\subsection{Input data}

Several independent or semi-dependent parameters were selected as actors in scenario, and they are: number of biologically active days, number of strong wind annual cases, precipitation extreme cases, and coastal erosion. These parameters are changing due to natural processes, including climate change as well. Climate change and variability of meteorological factors were estimated according to measurements in national meteorological station near Ainaži town ( $57^{\circ} 52^{\prime} 04.45^{\prime \prime} \mathrm{N}$ and $024^{\circ} 21^{\prime} 57.48^{\prime \prime} \mathrm{E}$; $6.1 \mathrm{~m}$ ASL BAS-77), which is located exactly within the territory of our case study area - in Salacgrīva municipality, near the border with Estonia.

Number of biologically active days indicate biological activity and could lead to watersheds flowering and decrease of water biological quality. This temperature indicator has been selected after discussion with water quality expert. Expert judgement was based on biological physiology of blue-green algae life cycle, flowering process and biological activity of other water plants that starts after stable temperature periods (over $10^{\circ} \mathrm{C}$ on daily average). Number of strong wind cases (very strong wind day cases according to seventh (over $13.8 \mathrm{~m} / \mathrm{s}$ ) Boffort class) indicate potential impact to erosion process. Precipitation extreme cases are analysed as number of cases exceeded 75th percentile. Analysis of historical data (1961-2015) shows strong decreasing tendency $\left(\mathrm{R}^{2}=0.2297 ; \mathrm{p}=0.05\right)$, and it is possible that this tendency will remain. In the nearest future potential decrease could achieve even $28 \%$ or precipitation extremes could decrease in average by 19 days during the year.

Coastal erosion process in Salacgrīva case is described by two variables - volume of primary dune (classified as a descriptor of volume) and volume of seashore silt (classified as a descriptor of volume). Measurements of both variables are done during 2016. Historical data were overviewed for trend analysis. According to historical data analysis, Salacgriva coastal line is merely affected by erosion. It is estimated that erosion process would not exceed $7 \mathrm{~m}$ in average until 2023, which means that it could be approximated that biogenic effect on erosion process is non-substantial.

Initially hypothetical universal system dynamics model structure was built for the whole coastal SES situation. This model included big amount of indicators, acting in different local coastal municipal development scenarios for Salacgrīva municipality: tourism extension, economic enhancement or "sleeping wagon scenario" for people working in national capital city, etc. Within expert and stakeholder discussions it was proposed that tourism development 
scenario should be analyzed more detailed due to several reasons: due to existing territory development plans, existing stakeholders' interest, past development and financial inputs. According to this assumption, some of variables could be neglected, e.g. birth rate, migration rate, etc. All parameters/variables included in tourism development scenario are listed in Table 1. In order to collect all needed data, external expert's advice and long-term measurement data, results from previous studies and research projects were used.

Table 1: Overview of base input data in the model.

\begin{tabular}{|c|c|c|c|c|}
\hline No & Parameter & Baseline value & Unit & Period \\
\hline 1 & $\begin{array}{l}\text { Number of biologically } \\
\text { active days with average air } \\
\text { temperature over } 10^{\circ} \mathrm{C}\end{array}$ & $114-158$ & Days/year & $1951-2015$ \\
\hline 2 & $\begin{array}{l}\text { Number of strong wind } \\
\text { cases }\end{array}$ & $12-89$ & Days/year & $1961-2015$ \\
\hline 3 & $\begin{array}{l}\text { Precipitation extremes as } \\
\text { 75th percentile exceedances }\end{array}$ & $38-130$ & Days/year & $1961-2015$ \\
\hline 4 & Visual change quality & $1-3$ & Indicator (code) & 2015 \\
\hline 5 & $\begin{array}{l}\text { Volume of primary dune, } \\
\text { class }\end{array}$ & $1-6$ & Absolute value & 2009-2016 \\
\hline 6 & $\begin{array}{l}\text { Volume of seashore silt, } \\
\text { class }\end{array}$ & $1-6$ & Absolute value & 2009-2016 \\
\hline 7 & Marine litter & 104 & $\begin{array}{c}\#(\text { pieces }) / 100 \mathrm{~m} \\
\text { beach length }\end{array}$ & $2012-2015$ \\
\hline 8 & $\begin{array}{l}\text { Noise pollution according to } \\
\text { number of vehicles }\end{array}$ & $\begin{array}{c}<2500 \\
2500-3500 \\
>3500\end{array}$ & dBA/daily & 1996-2015 \\
\hline 9 & $\begin{array}{l}\text { River (Salaca) ecological } \\
\text { quality indicator }\end{array}$ & Good & Indicator & 2010-2015 \\
\hline 10 & Swim water quality & Good & Indicator & $2010-2015$ \\
\hline 11 & Air pollution sources & $\begin{array}{l}19 \text { (stationary) } \\
4399 \text { (mobile) }\end{array}$ & $\begin{array}{c}\text { \#number and } \\
\text { abs/year }\end{array}$ & $2000-2014$ \\
\hline 12 & Number of mobile WC & 15 & Number (total) & 2016 \\
\hline 13 & Traffic flow & $2888-4399$ & $\begin{array}{c}\text { \#number } \\
\text { (vehicles)/daily }\end{array}$ & 1996-2015 \\
\hline 14 & Equipped sites & 10 & Number (total) & 2016 \\
\hline 15 & Number of visitors & $100-1000$ & \#number/day & 2015 \\
\hline
\end{tabular}

Complete conceptual system dynamics model is shown in Fig. 1. Complex modelling system consists of variables acting in different levels and subfields. These levels and subfields are based on SES approach, triple bottom line sustainability dimension and mandatory governance dimension (SEGS), e.g. economic development, stagnation, etc. In this case, tourism scenario was chosen and tested as the most realistic and stakeholders desired local coastal territory development scenario. Variables outside the tourism scenario 
were neglected (excluded) and input data preparation was performed depending on data availability and data sense. For example, climate change was estimated for long period (according to World Meteorological Organization, at least 30 years' period should be considered), while number of mobile WC is estimated only at present and as the function of attenders.

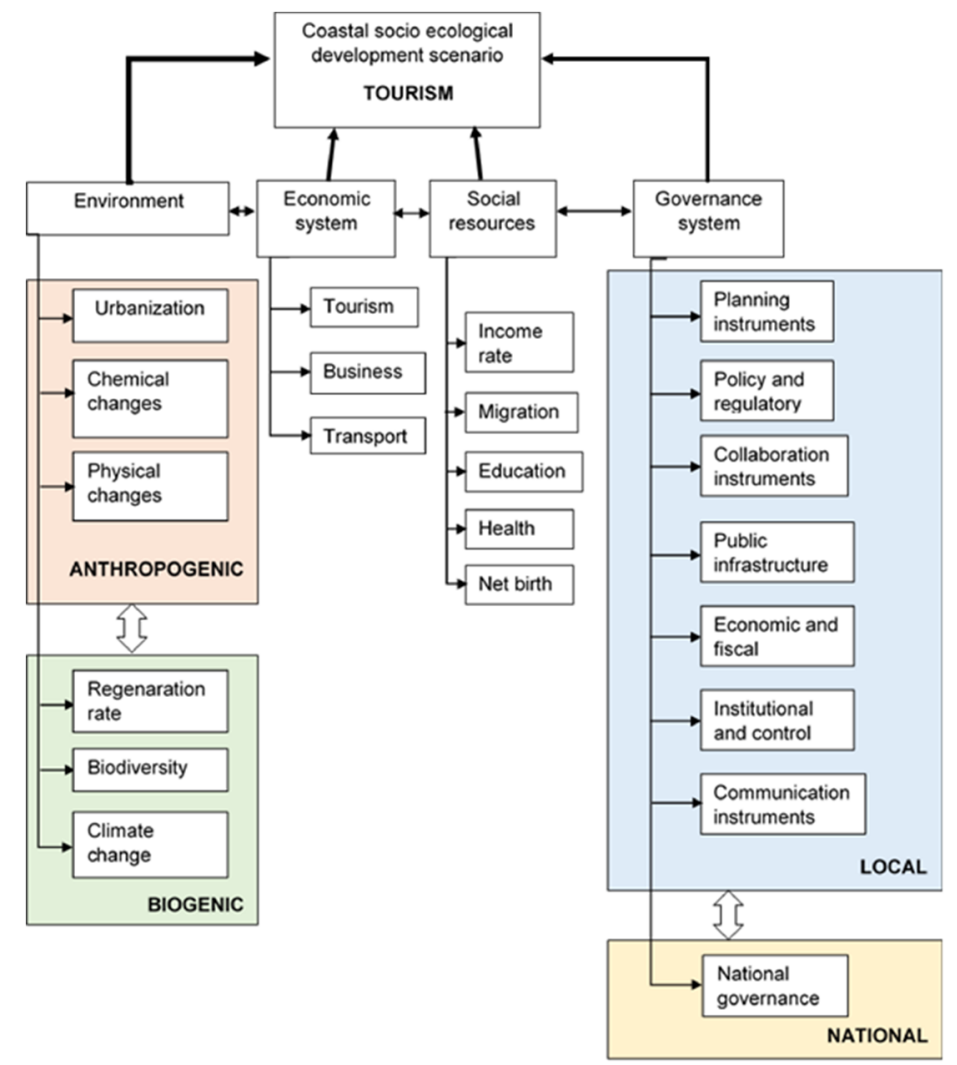

Figure 1: Conceptual system dynamic coastal SEGS model with general adaptation for Salacgrīva municipality.

\subsection{The model mathematical description}

From mathematical point of view, system model could be described as ARX polynomial black box model, consisting of linear structures, which have traditionally been useful for representing dynamic systems. Firstly, model system was built according to our and experts' understanding of direct, indirect and reverse links between variables set. Secondly, the model was optimized by measurement data and process of calibration that was implemented. Afterwards, scenario of tourism increase (by 30\%) was developed in order to find changes in other dependent variables. Some of parameters were set as constant, because non-substantial changes are not detected during period of interest. As a basic scenario, data from Table 1 were used. 
As inputs used in model are not comparable (e.g. number of tourist visitors during the days could reach about 1000 persons per day, but swim water quality is assessed as "good" based on Coli form bacteria), numerical analysis is not available. According to other authors publications [10], [16] non-comparable data could be converted to percentile form which is done in this case. Procedure used for data conversion is quite complex. For example, in case of marine litter assessment: (1) average number of marine litter collected along $100 \mathrm{~m}$ beach length is 104 pieces; (2) number of marine litter varies from 215 to 95, depending on year; (3) there is statistically substantial, but weak decreasing trend which varies in line with number of beach visitors; (4) according to above-written, in the interest of tourist increase, the number of marine litter in the future is calculated.

Substantiality of long-term climate changes was initially detected by trend analysis, while in case of substantial trend the extrapolation (or forecast) was done. In Salacgrīva case there is positive trend, detected in case of number of biologically active days, number of strong wind days, but decreasing trend in precipitation extremes.

Mainly, 4 driving forces were described: (1) climate change, (2) coastal changes, (3) environmental changes, and (4) structural changes that could be described as follows:

$$
\mathrm{ClC}=\mathrm{BAD} \times 0.13+\mathrm{SWD} \times 0.35-\mathrm{PED} \times 0.28,
$$

where $\mathrm{ClC}=$ climate change driving force, dimensionless; $\mathrm{BAD}=$ biologically active days, number; $\mathrm{SWD}=$ strong wind days, number; $\mathrm{PED}=$ precipitation extreme days, number.

$$
\mathrm{CoC}=\mathrm{VCQ} \times 0.05+\mathrm{VPD} \times 0.01+\mathrm{VSS} \times 0.01+\mathrm{ML} \times 0.05,
$$

where $\mathrm{CoC}=$ coastal changes driving force, dimensionless; $\mathrm{VCQ}=$ visual change quality, index; VPD = volume of primary dune, class; VSS = volume of seashore silt, class; $\mathrm{ML}=$ marine litter, number of pieces.

$$
\mathrm{EC}=\mathrm{NP} \times 0.05+\mathrm{SEQI} \times 0.05-\mathrm{SWQ} \times 0.01+\mathrm{APS} \times 0.1,
$$

where $\mathrm{EC}=$ environment changes driving force, dimensionless; $\mathrm{NP}=$ noise pollution, index; $\mathrm{SEQI}=$ Salaca ecological quality indicator, index; SWQ = swim water quality, index; APS $=$ air pollution sources, number.

$$
\mathrm{SC}=\mathrm{NM}_{\mathrm{WC}} \times 0.25+\mathrm{TF} \times 0.1+\mathrm{ES} \times 0.15+\mathrm{EBF} \times 0.10+\mathrm{E} \times 0.05+\mathrm{NV} \times 0.3,
$$

where $\mathrm{SC}=$ structural changes driving force, dimensionless; NMWC $=$ number of mobile $\mathrm{WC}$, number; $\mathrm{TF}=$ traffic flow, number of vehicles; $\mathrm{ES}=$ equipped sites, number; $\mathrm{EBF}=$ employment in biological farming, number; $\mathrm{E}=$ employment, number; $\mathrm{NV}=$ number of visitors, number.

All above-mentioned driving factors, including internal components, were mathematically described as a result of linear regression analysis. Prioritization of driving forces could look as follows (from most to less important): structural changes in ecosystem $(80 \%)$, coastal processes $(10 \%)$, environmental changes $(5 \%)$ and climate changes $(5 \%)$ that could be explained by the following expression (5):

$$
I \mathrm{~A}=\mathrm{SC} \times 0.8+\mathrm{EC} \times 0.05+\mathrm{CoC} \times 0.1+\mathrm{ClC} \times 0.05
$$

where IA = overall impact assessment, dimensionless; $\mathrm{SC}=$ structural changes driving force, dimensionless; $\mathrm{EC}=$ environment changes driving force, dimensionless; $\mathrm{CoC}=$ coastal changes driving force, dimensionless; $\mathrm{ClC}=$ climate change driving force, dimensionless.

Main system development drivers are described according to belonging activities and changes in parameters, while overall impact assessment was proposed to be calculated 
according to drivers impact importance: (1) climate change structural parameters are independent and cannot be affected by local human activities; (2) climate change impact as process driving force in whole system is minimal (about 5\%), which is mainly connected to system temporal frame (modelling is done for next five years); (3) the main changes are expected in "structural changes" force - about $80 \%$; (4) coastal changes are expected within $10 \%$.

\section{MODELLING RESULTS AND DISCUSSION}

Results are represented as expected changes (semi-quantitative grading) in the dependent variables from baseline condition, based on model runs. Following grading and criteria were used:

- "unimportant" $(+/-)$, expected changes are less than $1 \%$;

- "important" (++/- -$)$, expected changes are $1-35 \%$;

- "very important" (+++/---), expected changes are over $35 \%$.

Description of modelling results is given in Table 2.

Table 2: Overview of modelling results.

\begin{tabular}{|l|c|c|}
\hline Parameter/Process & Baseline & $\begin{array}{c}\text { Change from baseline } \\
(\%)\end{array}$ \\
\hline Number of biologically active days & 137 days & $++(13)$ \\
\hline Number of strong wind cases & 51 cases & $++(35)$ \\
\hline Precipitation extreme cases & 83 cases & $--(-28)$ \\
\hline Volume of primary dune & $2-4 \mathrm{~m}^{3} / \mathrm{m}$ & $+(<1)$ \\
\hline Volume of seashore & $10-15 \mathrm{~m}^{3} / \mathrm{m}$ & $+(<1)$ \\
\hline Visitors (tourists) & $1000 \# /$ day & $++(30)$ \\
\hline Mobile WC & 15 & $++(25)$ \\
\hline Traffic flow & 4399 & $+(10)$ \\
\hline Air pollution sources & 4418 & $+(10)$ \\
\hline Noise pollution sources, level & High & $+(5)$ \\
\hline Marine litter & 104 pieces & $+(5)$ \\
\hline Swim water quality & Good & $-(-1)$ \\
\hline Employment (crafts) & 15 & $+(5)$ \\
\hline Employment in biological farming, forestry & 10 & $+(10)$ \\
\hline Visual quality change & Good & $+/-(5 /-5)$ \\
\hline Salaca ecological quality indicator & Good & $-(-5)$ \\
\hline Equipped sites & 10 & $-(-15)$ \\
\hline
\end{tabular}

Modelling results show that even $30 \%$ increase of tourism flow could lead to some minor negative anthropogenic influence to ecosystem (e.g. increase of mobile pollution sources). On the other hand, there are expected some positive changes in socio-ecosystem - tourism scenario promotes economic income and other factors in the municipality. In some cases, influence is unclear, e.g. visual changes could be positive and negative as well. Also, participation of municipality in effective waste management is essential. Nevertheless, most 
changes are expected to be promoted by natural processes, e.g. climate change. Also, this result shows that tourism flow could increase by $30 \%$, indicating that tourism still has been underdeveloped and underestimated as area development promoter. More detailed discussion on this is provided further.

Overall, system dynamic approach shows high applicability for territory development planning purposes. Until now, other authors have been mainly focusing on specific species modelling in ecosystem (according to Foresters theory in 1970), close systems or impact of urbanization factors [6], [17]. This research describes wider approach, showing ability to include and describe complex governance, natural, social, economic, and other factors in the simplest possible way [18]. Authors found only one similar research concerning effect of fishing tourism in coastal municipality in Norway [10], where changes within system are analysed only based on stock accumulation (fishing intensity factor, fish life cycle), while other factors (social, governance and natural) were neglected.

It could be assumed that spatial coverage of results is strongly dependent on driving forces and modelling level. In case of governance impact assessment, even European legislation has some impact on situation in any single municipality. However, if there are modelled changes in natural processes, depending on process sporadicity, spatial coverage could vary from one specie meta niche (some kilometres) to even global processes (wind regime changes under climate change driving force). For Salacgrīva study spatial coverage borders are selected as municipality borders.

Additionally, model construction process was challenging because of insufficiency of some of data requiring developing the methods for data identification or interpretation of existing data. Some computation between data holders and problems to identify key processes and indicators required more detailed analysis, as dominantly external experts highlighted particular sphere as more important. Applied SAF methodology clearly shows practical applicability in various development strategies, even if development of territory is planned in opposite way. However, it should be noted that stakeholder's participation is essential to obtain vision of overall system. Unfortunately, passivity of interested groups is a limiting factor to develop site specific information within the model. In order to improve the model and test how it works in real life, some case activities, similar to other cases, should be considered [19]. During SAF implementation some failure to identify stakeholders was observed, which is explained by time consuming process during whole activity period. Alternatively, different communication ways should be considered, otherwise stakeholders will lose interest.

According to the obtained results, increase in the number of tourists by $30 \%$ in the coming years will understandably worsen environmental quality and practically in all fields (waste, water quality, air quality, noise level). However, many essential positive trends for municipal social economic development should also be observed, e.g. increase in the number of jobs, etc. Social economic development will occur in the context of local development, based directly in district coastal territory resources. In order to ensure softening/prevention of negative impacts, developed model can be used directly in planning of municipal budget expenditures-revenues, assessing as necessary investments part in appropriate fields - waste management, improvement of water supply systems, development of specific infrastructure for tourists in the coastal area. This would make tourism a potentially expected financial contribution source.

Used general/theoretical methodology during the research approved it's constructively practical applicability: 
1. System dynamics model identifies both the benefits of a particular development scenario and critical points. Therefore, it can serve as a basis for argumentation and target groups discussion about measures for critical impact reduction, development of new scenarios and assessment of different governance measures effectivity during the pre-introduction stage.

2. Municipality is perceived as closely interlinked system, and different level stakeholders are capable to identify their role and importance in the development process, regardless of whether it is local household, craftsmen, spatial development planner or top civil servant.

3. Developed complex system dynamic model is serving as a general spatial development basic dimensions framework model. In case of sectoral development, the general model can be comfortably "narrowed/actualized" depending on the needs of municipality and interested groups of society, excluding minimally influencing scenarios of development of those sectors, and more deeply studying essential parameters for specific sector.

4. Model identifying has also got very essential practical benefit both for the assessment of present situation and future planning. Sometimes there is an inadequacy of data in separate essential development areas - data might be too fragmented, too general or might not cover all involved areas and, therefore, development possibility assessments become limited. Therefore, society and decision makers have limited possibilities for adequate discussion and planning, which is particularly essential in the complex and controversial interests development areas (such as coastal resources and territory governance) and in their scenarios assessment (modelling).

\section{CONCLUSIONS}

The system dynamics conceptual model, designed in the framework of SAF methodology and further elaborated for STELLA application, presented here for complex coastal socioecological system, is a first attempt in Latvia to understand the main interactions between climate change, coastal changes, environmental and structural changes in coastal rural municipalities at an integrated quantitative approach. In this research, the case of coastal tourism intensive development in Salacgrīva coastal municipality was studied.

The study has highlighted challenges related to the development and implementation of the model with components in different fields. Within the SAF process, the initially prepared system description with selected 40 factors has been generalized by selected 15 key factors, which allows to describe the system more sufficiently and completely. The key factors were included into the model to describe live and open, and simultaneously complex coastal system. Detailed analysis, formulation process indicates main four agglomerated process drivers - environmental, coastal, climate and structural, where structural changes indicate the most impressive impact.

Elaborated tourism scenario shows that increase of tourists will have comparatively minor influence on coastal socio-ecosystem in case of adequate planning measures. It is expected that even climate change impact will be more evident. During the experts and stakeholders' discussions, SAF application has shown positive practical results for several reasons:

- during the model development phase crucial data and knowledge gaps were identified, leading to practical steps and solutions between any new measures and future scenarios;

- discussion within stakeholders group gives them opportunity to actively participate in municipality development and spatial planning processes; 
- developed model shows kind of universality, which means that the model could be reduced or made wider according to necessity of particular socio-ecological governance system at any development point.

- Key leverage points for application measures to be developed within following overall decision-making process are visible within the model structure.

Approbated conceptual complex system dynamics model and STELLA modelling software approach show their eventual applicability and flexibility, which makes it possible to use them for other processes, territories and different local coastal/municipal development scenarios.

\section{ACKNOWLEDGEMENTS}

The authors would like to thank Salacgrīva municipality, all the experts and stakeholders, who were very cooperative and helpful for designing and testing of this case study. Funding acknowledgements are given to the EU BONUS programme BaltCoast project - A Systems Approach Framework for Coastal Research and Management in the Baltics (call 2014-2015). BONUS BaltCoast has received funding from BONUS (Art 185), funded jointly from the European Union's Seventh Programme for research, technological development and demonstration and from the State Education Development Agency national grant of the Republic of Latvia (B/2015/4).

\section{REFERENCES}

[1] Ali, M., Hadi, S. \& Sulistyantara, M., Study on land cover change of Ciliwung downstream watershed with spatial dynamic approach. Procedia - Social and Behavioural Sciences, 227, pp. 52-59, 2016.

[2] Ballé-Béganton, J. et al., A modelling platform for complex socio-ecosystems: An application to freshwater management in coastal zones. Proceedings of International Congress on Environmental Modelling and Software, pp. 264-274, 2010.

[3] Kok, J.-L., Engelen, G. \& Maes, J., Reusability of model components for environmental simulation: Case studies for integrated coastal zone management. Environmental Modelling and Software, 68, pp. 42-54, 2015.

[4] Moksness, E. et al., Effects of fishing tourism in a coastal municipality: A case study from Risør, Norway. Ecology and Society, 16(3), p. 11, 2011.

[5] European Commission, Science for Environment Policy. Thematic issue: Coastal zones: Achieving sustainable management, Issue 46, 2014.

[6] Mavrommati, G., Bithas, K. \& Panayiotidis, P., Operationalizing sustainability in urban coastal systems: A system dynamics analysis. Water Research, 47, pp. 72357250, 2013.

[7] Rich, K.M., Rich, M. \& Dizyee, K., Participatory systems approaches for urban and peri-urban agriculture planning: The role of system dynamics and spatial group model building. Agricultural Systems, 160, pp. 110-123, 2018.

[8] Hopkins, T.S., Bailly, D. \& Stottrup, J.G., A systems approach framework for coastal zones. Ecology and Society, 16(4), pp. 25-37, 2011.

[9] Systems Approach Framework (SAF) Handbook, 2016. http://www.coastal-saf.eu/ introduction/index.shtml. Accessed on: 10 Jun. 2020.

[10] Costanza, R. \& Voinov, A., Modelling ecological and economic systems with STELLA: Part III. Ecological Modelling, 143, pp. 1-7, 2001. 
[11] Kotira, J.H. et al., A system dynamics simulation model for sustainable water resources management and agricultural development in the Volta River Basin, Ghana. Science of the Total Environment, 573, pp. 444-457, 2016.

[12] Marzouk, M. \& Azab, S., Analyzing sustainability in low-income housing projects using system dynamics. Energy and Buildings, 134, pp. 143-153, 2017.

[13] Park, S., Sahleh, V. \& Jung, S.Y., A system dynamics computer model to assess the effects of developing an alternate water source on the water supply systems management. Procedia Engineering, 119, pp. 753-760, 2015.

[14] Waltersa, J.P. et al., Exploring agricultural production systems and their fundamental components with system dynamics modelling. Ecological Modelling, 333, pp. 51-65, 2016.

[15] Wang, Y.F., Li, B. \& Zhang, B., Probability prediction and cost benefit analysis based on system dynamics. Process Safety and Environmental Protection, 114, pp. 271-278, 2018.

[16] Espinoza, A. et al., Sustainability assessment to support governmental biodiesel policy in Colombia: A system dynamics model. Journal of Cleaner Production, 141, pp. 1145-1163, 2017.

[17] Kudrenickis, I. et al., System approach methodology framework adaptation for governance development scenarios: Salacgriva coastal municipality. Proceedings of 75th Scientific Conference, University of Latvia, Riga, Latvia, pp. 314-318, 2017. (In Latvian.)

[18] Elsawah, S. et al., An overview of the system dynamics process for integrated modelling of socio-ecological systems: Lessons on good modelling practice from five case studies. Environmental Modelling and Software, 93, pp. 127-145, 2017.

[19] Guo, L., Qu, Y., Wu, C. \& Wang, X., Identifying a pathway towards green growth of Chinese industrial regions based on a system dynamics approach. Resources, Conservation and Recycling, 128, pp. 143-154, 2018. 